\title{
Program Linier Parametrik
}

\author{
Adolf T. Simatupang \\ Politeknik Negeri Bandung, Jl. Gegerkalong Hilir, Ciwaruga, Parongpong, Kabupaten Bandung \\ Barat, Jawa Barat 40559 \\ ${ }^{*}$ Corresponding Author. E-mail: adolf.juan@yahoo.com
}

\begin{abstract}
Abstrak
Penelitian ini bertujuan untuk membahas suatu masalah program linier dimana konstantakonstantanya dapat berubah - ubah, jika suatu konstanta pada masalah program linier dirubah, maka kita tidak perlu menghitung mulai dari awal lagi. Selanjutnya akan mengkaji sifat-sifat fungsi objektifnya akibat dari perubahan konstanta tersebut. Dalam pembahasan ini menentukan "nilai kritis" non negatif yang memberikan solusi optimal untuk masalah program linier parametrik. Pencarian nilai kritis pada program linier parametrik dilakukan dengan metode versi matriks.

Kata kunci: Fungsi Objektif; Parametrik; Konstrain; Nilai Kritis; Solusi Optimal
\end{abstract}

\begin{abstract}
This study aims to discuss a linear program problem where its constants can change, If a constant for a linear program problem is changed, then we don't need to count from the beginning again. Next, we will examine the properties of the objective function as a result of changes in these constants. In this discussion determine the non-negative "critical value" which provides the optimal solution to the problem of parametric linear programs. Searching for critical values in parametric linear programs is done by the matrix version method.
\end{abstract}

Keywords: Constraint; Critical Value; Objective Function; Optimal Solution; Parametric

\section{PENDAHULUAN}

Pada masalah program linier, koefisien fungsi objektif maupun koefisien pembatasnya selalu konstan. Masalah program linier ini dapat diselesaikan dengan metoda simpleks biasa. Jika kita ingin merubah suatu nilai dari konstanta-konstanta yang ada, baik itu konstanta fungsi objektif maupun konstanta pembatas, maka kita akan mulai menghitung dari awal lagi, untuk menghasilkan solusi optimum. Maka diperlukan suatu solusi agar dapat menentukan soluso optimum.

Berdasarkan beberapa penelitian yang telah dilakukan sebelumnya penerapan program linier telah digunakan dalam beberapa penelitian. (Indriani, Suyitno, \& Mashuri, 2013;
Suwirmayanti, 2017; Windarti, 2013) Namun, belum adanya penelitian yang membahas mengenai program linier parametrik. Berdasarkan penelitian terdahulu keterbaruan penelitian ini terletak pada penentuan "nilai kritis" non negatif yang memberikan solusi optimal untuk masalah program linier parametric. Maka, tujuan penelitian ini adalah untuk membahas mengenai program linier parametrik

\section{METODE PENELITIAN}

Penelitian ini merupakan penelitian studi pustaka. Penelitian ini mengambil dari beberapa buku sebagai referensi (Ayres, 1984; Dhawan, 1975; Hadly, 1962; Taha, 2003) 


\section{HASIL DAN PEMBAHASAN}

\section{PROGRAM LINIER FUNGSI OBJEKTIF PARAMETRIK}

Masalah program linier sebelum diberi parameter adalah

$$
\text { Maks } \mathrm{z}=\mathrm{C} \mathrm{X}
$$

terhadap $(\mathrm{A}, \mathrm{I}) \mathrm{X}=\mathrm{P}_{0}, \mathrm{P}_{0}$

$\geq 0$

$$
\mathrm{X} \geq 0
$$

Disini kita membahas variasi linier vektor

C. Misalkan $\theta \geq 0$ adalah parameter variasi. Maka fungsi-fungsi linier dalam koefisien program linier di atas menjadi:

${ }^{\theta} \mathrm{C}={ }^{\mathrm{O}} \mathrm{C}+\theta \cdot \mathrm{E}$

$$
=\left({ }^{\circ} \mathrm{C}_{1},{ }^{\mathrm{o}} \mathrm{C} 2, \ldots,{ }^{\mathrm{o}} \mathrm{C}_{\mathrm{m}+\mathrm{n}}\right)+\theta\left(\mathrm{e}_{1}, \mathrm{e}_{2}, \mathrm{e}_{\mathrm{m}+\mathrm{n}}\right) \ldots
$$

Konstanta-konstanta ${ }^{\circ} \mathrm{C}, \quad \mathrm{E}$ diketahui. Disini kita meninjau $\theta \geq 0$. Untuk $\theta \leq 0$ peninjauannya dilakukan dengan cara yang sama.

Perhatikan bahwa ${ }^{\circ} \mathrm{C}$ diperoleh dari fungsi- fungsi di atas dengan mengambil $\theta$ $=0$.

Selanjutnya masalah yang kita tinjau adalah masalah memaksimumkan, sedangkan masalah meminimumkan dapat ditinjau dengan cara yang sama.

\section{VARIASI LINIER PADA VEKTOR C}

Tahap pertama untuk $\theta=0$, yaitu diambi $C$ $={ }^{\circ} \mathrm{C}$ Misalkan $\mathrm{X}_{\mathrm{B}}={ }^{\circ} \mathrm{B}^{-1} \mathrm{P}_{0}$, solusi optimalnya Maka untuk iterasi optimalnya berlaku:

${ }^{\circ} \mathrm{Z}_{\mathrm{j}}-{ }^{\circ} \mathrm{C}_{\mathrm{j}} \geq 0$, untuk semua vektor non basis $\mathrm{P}_{\mathrm{j}}$, yaitu ${ }^{\circ} \mathrm{C}_{\mathrm{B}} \cdot{ }^{\circ} \mathrm{B}^{-1} \cdot \mathrm{P}_{\mathrm{j}}-{ }^{\circ} \mathrm{C}_{\mathrm{j}} \geq 0$, untuk semua vektor non basis $\mathrm{P}_{\mathrm{j}}$.

Kemudian kita meninjau masalah program linier untuk $\theta>0$, dimana ${ }^{\circ} \mathrm{C}={ }^{\circ} \mathrm{C}$ $+\theta \mathrm{E}$

Dari definisi matriks pada Tabel simpleks, setiap variasi pada $\mathrm{C}$ hanya mempengaruhi koefisien koefisien fungsi objektif, yaitu $Z_{j}-C_{j}$. Koefisien itu hanya keoptimalan yang perlu diselidiki. Prosedur ini akan menentukan nilai $\theta$ berturut turut dimana solusi basis optimal berubah Nilai $\theta$ ini disebut nilai kritis dengan $\theta \geq 0$.
Pada nilai $\theta=0$, solusi optimalnya ${ }^{\circ} \mathrm{X}_{\mathrm{B}}$.

Pada nilai $\theta=\alpha$, misalkan solusi optimalnya diketahui ${ }^{0} \mathrm{X}_{\mathrm{B}}$.

Kita akan menenukan nilai kritis berikutnya $\beta, \alpha<\beta$ untuk $\theta \geq \alpha$ berlaku:

${ }^{\mathrm{e}} \mathrm{C}_{\mathrm{B}}={ }^{\circ} \mathrm{C}_{\mathrm{B}}+\theta^{\circ} \mathrm{E}_{\mathrm{B}}$

$$
\begin{aligned}
& ={ }^{\circ} C_{B}+\alpha E_{B}+\theta \cdot E_{B}-\alpha E_{B} \\
& ={ }^{0} C_{B}+(\theta-\alpha) E_{B}
\end{aligned}
$$

Demikian juga untuk $0 \geq \alpha$

${ }^{\theta} \mathrm{Cj}={ }^{\alpha} \mathrm{Cj}+(\theta-\alpha)$ ej

Jadi ${ }^{\theta} \mathrm{Zj}-{ }^{\theta} \mathrm{C}_{\mathrm{j}}={ }^{\theta} \mathrm{C}_{\mathrm{B}} \cdot{ }^{\alpha} \mathrm{B}^{-1} \mathrm{Pj}-{ }^{\theta} \mathrm{C}_{\mathrm{j}}$

$=\left\{{ }^{\alpha} C_{B}+(\theta-\alpha) E_{B}{ }^{\alpha} B^{-1} \cdot P j\left\{{ }^{\alpha} C j+(\theta-\alpha) e_{j}\right\}\right.$ $={ }^{\alpha} C_{B} \cdot{ }^{\alpha} B^{-1} \mathrm{Pj}-{ }^{\alpha} C j+(\theta-\alpha)\left(E_{B}-{ }^{\alpha} B^{-1} P_{j}-\right.$ ej)

$$
=\left({ }^{\alpha} \mathrm{Zj}-{ }^{\alpha} \mathrm{Cj}\right)+(\theta-\alpha)\left(\mathrm{E}_{B} \cdot{ }^{\alpha} \mathrm{B}^{-1} \mathrm{Pj}-\mathrm{ej}_{\mathrm{j}}\right)
$$

Supaya solusi menjadi optimal untuk $\theta \geq \alpha$, maka kondisi ${ }^{\alpha} \mathrm{Zj}-{ }^{\alpha} \mathrm{Cj} \geq 0$ harus berlaku untuk setiap j. Karena ${ }^{\alpha} \mathrm{Zj}-{ }^{\alpha} \mathrm{Cj} \geq 0$, maka dari (1.1.1) diperoleh:

(1) Bila $\left(E_{B}{ }^{\alpha} B^{-1} \mathrm{Pj}\right.$ ej$) \geq 0, \mathrm{Vj}$, maka kondisi optimal dipenuhi dan ${ }^{\alpha} \mathrm{X}_{\mathrm{B}}$ tetap soiusi optimal untuk $\theta \geq \alpha$.

(2) Bila $\left(\mathrm{E}_{\mathrm{B}}{ }^{\alpha} \mathrm{B}^{-1} \cdot \mathrm{Pj} \cdot \mathrm{ej}\right)<0$, untuk sekurang kurangnya satu $\mathrm{j}$, maka terdapat nilai kritis $\theta=\beta$ yang diberikan oleh

$$
\begin{aligned}
& \beta=\quad \begin{array}{l}
\alpha \\
\left\{\frac{-\left({ }^{\alpha} Z_{j}-{ }^{\alpha} C_{j}\right)}{E_{B} \cdot{ }^{\alpha} B^{-1} P_{j}-e_{j}} \mid\right.
\end{array} \mid\left(E_{B} \cdot{ }^{\alpha} B^{-1} P_{j}-e_{j}\right)
\end{aligned}
$$

Ambil $\mathrm{X}_{\mathrm{K}}$ variabel non basis yang berhubungan dengan $\beta$ dimana $\beta$ dihubungkan dengan minimal hasil bagi di atas, variabei $\mathrm{X}_{\mathrm{K}}$ merupakan variabel masuk. Variabel basis yang berhubungan dengan nilai ratio minimum merupakan variabel keluar, sehingga $Z_{K}-C_{K}=0$ pada $\theta$ $=\beta$.

Maksudnya bahwa pada $0=p$, ada solusi yang dipilih untuk $0>\mathrm{p}$, di mana solusi basis " $\mathrm{X}_{\mathrm{B}}(\mathrm{a}<\mathrm{P})$ akan menjadi solusi optimal. Selanjutnya setelah diperoleh variabel masuk dan variabel keluar pada 0 $=\mathrm{p}$, maka masalah program linier parametrik di atas diselesaikan dengan OBE (Operasi Baris Elementer), sehingga 
hasil-hasil optimal yang dipilih pada $0=p$ adalah ${ }^{\mathrm{P}} \mathrm{X}$.

Prosedur di atas diulang pada ${ }^{\wedge} \mathrm{XB}$ untuk mendapatkan nilai kritis yang berturutturut, maka pada range terakhir, yang mana "Xg tetap optimal.

\section{Contoh:}

Tinjau masalah

Maks $\mathrm{Z}=(3-6 \theta) \mathrm{x}_{1}+(2-2 \theta) \mathrm{x}_{2}+(5+$ 50) $\mathrm{x}_{3}$

$$
\begin{aligned}
& \text { terhadap } \mathrm{x}_{1}+2 \mathrm{x}_{2}+\mathrm{x}_{3}+\mathrm{x}_{4}=430 \\
& 3 \mathrm{x}_{1}+2 \mathrm{x}_{3}+\mathrm{x}_{5}=460 \\
& \mathrm{x}_{1}+4 \mathrm{x}_{2}+\mathrm{x}_{6}=420 \\
& \mathrm{x}_{1}, \mathrm{x}_{2}, \ldots, \mathrm{x}_{6} \geq 0
\end{aligned}
$$

Disini $\mathrm{x}_{4}, \mathrm{x}_{5}, \mathrm{x}_{6}$ merupakan variabelvariabel slack, dan

${ }^{\theta} \mathrm{C}={ }^{\circ} \mathrm{C}+0 \mathrm{E}=(3,2,5)+\theta(-6,-2,5)$

Jika $\theta=0$, masalah program linier parametrik di atas diselesaikan dengan metode simpleks, maka Tabel solusinya sebagai berikut:

Tabel 1. Hasil Penyelesaian Nilai-Nilai Variabel

\begin{tabular}{ccccccccc}
\hline Basis & $\mathrm{z}$ & $\boldsymbol{x}_{\mathbf{1}}$ & $\boldsymbol{x}_{\mathbf{2}}$ & $\boldsymbol{x}_{\mathbf{3}}$ & $\boldsymbol{x}_{\mathbf{4}}$ & $\boldsymbol{x}_{\mathbf{5}}$ & $\boldsymbol{x}_{\mathbf{6}}$ & Solusi \\
$\mathrm{z}$ & 1 & 4 & 0 & 0 & 1 & 2 & 0 & 1350 \\
$\mathrm{X} 2$ & 0 & $-1 / 4$ & 1 & 0 & $1 / 2$ & $-1 / 4$ & 0 & 100 \\
$\mathrm{X} 3$ & 0 & $3 / 2$ & 0 & 1 & 0 & $1 / 2$ & 0 & 230 \\
$\mathrm{X}_{6}$ & 0 & 2 & 0 & 0 & -2 & 1 & 1 & 20 \\
\hline
\end{tabular}

Dari Tabel 1. terlihat bahwa $\mathrm{x}_{2}, \mathrm{x}_{3}, \mathrm{x}_{6}$ merupakan variabel basis sedangkan $\mathrm{x} 1$, $\mathrm{X}_{4}, \mathrm{X} 5$ variabel tak basis, jadi:

$$
\begin{aligned}
& { }^{\mathrm{o}} \mathrm{X}_{\mathrm{B}}=\left(\begin{array}{l}
\mathrm{x}_{2} \\
\mathrm{x}_{3} \\
\mathrm{x}_{6}
\end{array}\right)=\left(\begin{array}{c}
100 \\
230 \\
20
\end{array}\right) \\
& { }^{\mathrm{o}} \mathrm{B}^{-1}=\left(\begin{array}{ccc}
\frac{1}{2} & -\frac{1}{4} & 0 \\
0 & \frac{1}{2} & 0 \\
-2 & 1 & 1
\end{array}\right)
\end{aligned}
$$$$
\text { dan }
$$

$E_{B}=(-2,5,0), P_{j}=\left(P_{1}, P_{4}, P_{5}\right)=\left(\begin{array}{lll}1 & 1 & 0 \\ 3 & 0 & 1 \\ 1 & 0 & 0\end{array}\right)$ dan $e_{j}=\left(e_{1}, e_{4}, e_{5}\right)=(-6,0,0)$

Sekarang kita menentukan nilai $\theta=0^{\prime}>0$. Apakah $\left(E_{B}{ }^{\circ} B^{1} P_{j}-e_{j}\right)>0, V_{j}, j \in J$. $\mathrm{J}=$ himpunan indeks variabel non basis $=\{1,4,5\}$
$(-2,5,0)\left(\begin{array}{ccc}\mathrm{E}_{B} & { }^{\circ} \mathrm{B}^{-1} & \left.\cdot \mathrm{Pj}-\mathrm{e}_{\mathrm{j}}\right)= \\ \frac{1}{2} & -\frac{1}{4} & 0 \\ 0 & \frac{1}{2} & 0 \\ -2 & 1 & 1\end{array}\right)\left(\begin{array}{lll}1 & 1 & 0 \\ 3 & 0 & 1 \\ 1 & 0 & 0\end{array}\right)-(6,0,0)=$ $(14,-1,3)$

Variabel non basis yang mempunyai nilai $\left(\mathrm{E}_{\mathrm{B}}-{ }^{\circ} \mathrm{B} 1 \cdot \mathrm{Pj}-\mathrm{ej}\right)<0$ adalah $\mathrm{x} 4$.

sehingga $\mathrm{X}_{4}$ merupakan variabel masuk.

Jadi $\theta^{\prime}=\theta^{0}+\left\{\frac{-\left({ }^{\mathrm{O}} \mathrm{Z}_{4}-{ }^{\mathrm{O}} \mathrm{C}_{4}\right)}{\mathrm{E}_{\mathrm{B}} \cdot{ }^{\circ} \mathrm{B}^{-1} \mathrm{P}_{4}-\mathrm{e}_{4}} \mid=0+\frac{-1}{-1}=1\right.$

Kemudian kita mencari variabel keluar dari Tabel 1.1.1. Karena $\mathrm{x}_{4}$ merupakan variabel masuk, maka nilai ratio minimum adalah

$=\min \left\{\frac{100}{\frac{1}{2}},-,--\right\}=200$

Jadi ratio minimum 200 adalah variabel $\mathrm{x}$, sehingga variabel basis $\mathrm{x}_{2}$ merupakan variabel keluar. Maka masalah program linier parametrik pada Tabel 1 diselesaikan dengan OBE, sehingga Tabel menjadi:

Tabel 2. Hasil Perhitungan OBE

\begin{tabular}{ccccccccc}
\hline Basis & $\mathrm{z}$ & $\boldsymbol{x}_{\mathbf{1}}$ & $\boldsymbol{x}_{\mathbf{2}}$ & $\boldsymbol{x}_{\mathbf{3}}$ & $\boldsymbol{x}_{\mathbf{4}}$ & $\boldsymbol{x}_{\mathbf{5}}$ & $\boldsymbol{x}_{\mathbf{6}}$ & Solusi \\
$\mathrm{z}$ & 1 & 18 & 0 & 0 & 0 & 5 & 0 & 2300 \\
$\mathrm{X}_{4}$ & 0 & $-1 / 2$ & 2 & 0 & 1 & $-1 / 2$ & 0 & 200 \\
$\mathrm{X}_{3}$ & 0 & $3 / 2$ & 0 & 1 & 0 & $1 / 2$ & 0 & 230 \\
$\mathrm{X}_{6}$ & 0 & 1 & 4 & 0 & 0 & 0 & 1 & 420 \\
\hline
\end{tabular}

Cara menghitung koefisien persamaan fungsi objektif pada Tabel 2 sebagai berikut:

${ }^{0} \mathrm{Zj}-{ }^{0} \mathrm{Cj}=\left({ }^{0} \mathrm{Zj}_{\mathrm{j}}-{ }^{0} \mathrm{C}_{\mathrm{j}}\right)+\theta^{\prime}\left(\mathrm{E}_{\mathrm{B}} \cdot{ }^{0} \mathrm{~B}^{-1} \cdot \mathrm{P}_{\mathrm{j}}-\mathrm{e}_{\mathrm{j}}\right)$

maka:

${ }^{\theta_{Z_{1}}-{ }^{\theta} \mathrm{C}_{1}=4+1(14)=18}$

${ }^{\theta} \mathrm{Z}_{4}-{ }^{\theta} \mathrm{C}_{4}=1+1(-1)=0$

${ }^{\theta_{\mathrm{Z}}}-{ }^{\theta} \mathrm{C}_{5}=2+1(3)=5$

Dari Tabel 1.1.2 terlihat bahwa $\mathrm{x}_{4}, \mathrm{x}_{3}, \mathrm{x}_{6}$ merupakan variabel basis. Sedangkan $\mathrm{x}_{1}$, $\mathrm{X} 2$, X5 variabel tak basis, Jadi: 
Desimal, 2 (1), 2019 - 72

Adolf T. Simatupang

${ }^{\mathrm{O}} \mathrm{X}_{\mathrm{B}}=\left(\begin{array}{l}\mathrm{x}_{4} \\ \mathrm{x}_{3} \\ \mathrm{x}_{6}\end{array}\right)=\left(\begin{array}{l}200 \\ 230 \\ 420\end{array}\right)$ dan ${ }^{\mathrm{O}} \mathrm{B}^{-1}=\left(\begin{array}{ccc}1 & -\frac{1}{2} & 0 \\ 0 & \frac{1}{2} & 0 \\ 0 & 0 & 1\end{array}\right)$

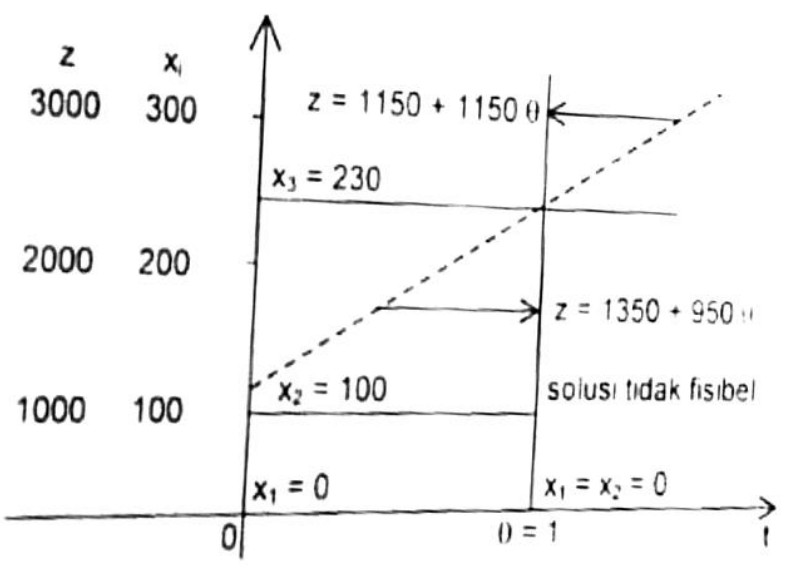

Sekarang kita menentukan nilai $\theta=\theta^{\prime \prime}>\theta$ " Apakah $\left(\mathrm{E}_{\mathrm{B}}-0^{\text {"B }} \mathrm{B}^{-1} \cdot \mathrm{P}_{\mathrm{j}}-\mathrm{e}_{\mathrm{j}}\right) \geq 0, \mathrm{v}_{\mathrm{j}}, \mathrm{j} \in \mathrm{J}$, $\mathrm{J}=\{1,2,5\}$

$\left(\mathrm{E}_{\text {B }} \cdot 0^{\prime \prime} \mathrm{B}^{-1} \cdot \mathrm{P}_{\mathrm{j}}-\mathrm{e}_{\mathrm{j}}\right)=(0,5,0)$ $\left(\begin{array}{ccc}1 & -\frac{1}{2} & 0 \\ 0 & \frac{1}{2} & 0 \\ 0 & 0 & 1\end{array}\right)\left(\begin{array}{lll}1 & 2 & 0 \\ 3 & 0 & 1 \\ 1 & 4 & 0\end{array}\right)-(-6,-2,0)$ $\left(\frac{27}{2}, 2, \frac{5}{2}\right)$

Karena $\left(\mathrm{E}_{\mathrm{B}} \cdot{ }^{\theta} \mathrm{B}^{-1} \cdot \mathrm{P}_{\mathrm{j}}-\mathrm{e}_{\mathrm{j}}\right) \geq 0, \forall_{\mathrm{j}}, \mathrm{j} \in \mathrm{J}=(1$, $2,5)$, maka kondisi ${ }^{\theta} \mathrm{zj}-{ }^{\theta} \mathrm{Cj}_{\mathrm{j}} \geq 0$ terpenuhi untuk semua $\theta \geq \theta^{\prime}=1$

Jadi solusi optimal telah tercapai untuk nilai $\theta>\theta^{\prime}=1$. Solusi optimal untuk $\theta>0$ dapat dinyatakan seperti pada Gambar 1 .

Untuk $0<\theta<1$, variabel-variabel basisnya adalah $\mathrm{X}_{\mathrm{B}}=\left(\mathrm{x}_{2}, \mathrm{X}_{3}, \mathrm{x}_{\mathrm{S}}\right)^{\mathrm{T}}=(100,230,20)^{\mathrm{T}}$

Maka $\mathrm{z}={ }^{\mathrm{e}} \mathrm{C}_{\mathrm{B}} \cdot{ }^{\circ} \mathrm{X}_{\mathrm{B}}=(2-2 \theta, 5+5 \theta, 0)\left(\begin{array}{c}100 \\ 230 \\ 20\end{array}\right)$ $=(1350+950 \theta)$

untuk $\theta \geq 1, \mathrm{x}_{\mathrm{B}}=\left(\mathrm{x}_{4}, \mathrm{x}_{3}, \mathrm{x}_{6}\right)^{\mathrm{T}}=(200,230$, $420)^{\mathrm{T}}$

Jadi $\mathrm{z}={ }^{\theta}{ }_{\mathrm{CB}} \cdot{ }^{\theta} \mathrm{XB}=(0,5+5 \theta, 0)\left(\begin{array}{l}200 \\ 230 \\ 420\end{array}\right)=1150$ $+1150 \theta$

Terlihat pada Gambar 1, koefisien keuntungan $x_{1}$ dan $x_{2}$ adalah menurun untuk semua $\theta$, sehingga kedua variabel $i$ merupakan variabel keluar dari solusi. Sedangkan variabel dari $x_{3}$ tetap merupakan variabel solusi karena koefisien keuntungan dari koefisien $x_{3}$ adalah naik untuk semua $\theta$.

Apabila masalah program linier parametrik di atas dilanjutkan, maka:

${ }^{\theta} \mathrm{C}_{\mathrm{B}} \cdot{ }^{0 \prime} \mathrm{B}-1=(0,5+5 \theta, 0)\left(\begin{array}{ccc}1 & -\frac{1}{2} 0 & \\ 0 & \frac{1}{2} & 0 \\ 0 & 0 & 1\end{array}\right)=$

$\left(0, \frac{5+5 \theta}{2}, 0\right)$

karena vektor-vektor $\mathrm{P}_{1}, \mathrm{P}_{2}$, dan $\mathrm{P}_{5}$ adalah vektor-vektor non basis, maka:

${ }^{\mathrm{B}} \mathrm{Z}-{ }^{\theta} \mathrm{Cj}=$

$={ }^{\theta} \mathrm{C}_{\mathrm{B}} \cdot{ }^{\theta \prime} \mathrm{B}^{-1}\left(\mathrm{P}_{1}, \mathrm{P}_{2}, \mathrm{P}_{5}\right)\left({ }^{\theta} \mathrm{C}_{1},{ }^{\theta} \mathrm{C}_{2},{ }^{\theta "} \mathrm{C}_{5}\right)$

$=\left(0, \frac{5+5 \theta}{2}, 0\right)\left(\begin{array}{lll}1 & 2 & 0 \\ 3 & 0 & 1 \\ 1 & 4 & 0\end{array}\right)-(3-6 \theta, 2-2 \theta, 0)$

$=\left(\frac{9+27 \theta}{2},-2+2 \theta, \frac{5+5 \theta}{2}\right)$

Jadi untuk $0 \geq 1,{ }^{\theta} \mathrm{Z}_{\mathrm{j}}-{ }^{\theta} \mathrm{C}_{\mathrm{j}}$ adalah non negatif. 
PROGRAM LINIER KONSTRAIN KANAN PARAMETRIK

Masalah program linier sebelum diberi parameter adalah

Maks z $=\mathrm{C} \cdot \mathrm{X}$

terhadap $(\mathrm{A}, \mathrm{I}) \mathrm{X}=\mathrm{P}_{0}, \mathrm{P}_{0}>0$

$$
\mathrm{X}>0
$$

Disini kita membahas variasi linier vektor $\mathrm{P}_{0}$. Misalkan $\theta>0$ adalah parameter variasi. Maka fungsi-fungsi linier dalam koefisien-koefisien program linier di atas menjadi:

${ }^{\theta} \mathrm{P}_{0}={ }^{\theta} \mathrm{P}_{0}+\theta \cdot b=\left(\begin{array}{c}{ }^{\mathrm{o}} \mathrm{P}_{\mathrm{O} 1} \\ { }^{\mathrm{o}} \mathrm{P}_{\mathrm{O} 2} \\ { }_{\mathrm{M}} \\ { }^{\circ} \mathrm{P}_{\mathrm{Om}}\end{array}\right)+\theta\left(\begin{array}{c}\mathrm{b}_{1} \\ \mathrm{~b}_{2} \\ \mathrm{M}_{\mathrm{m}} \\ \mathrm{b}_{\mathrm{m}}\end{array}\right)$

Konstanta-konstanta ${ }^{\mathrm{O}} \mathrm{P}_{\mathrm{O}}, \mathrm{b}$ diketahui. Disini kita meninjau $\theta \geq 0$. Untuk $\theta \leq 0$ peninjauannya dilakukan dengan cara yang sama. Perhatikan bahwa op diperoleh dari fungsi-fungsi di atas dengan mengambil $\theta=0$.

Selanjutnya masalah yang kita tinjau adalah masalah memaksimumkan, sedangkan masalah meminimumkan dapat ditinjau dengan cara yang sama.

\section{VARIASI LINIER PADA VEKTOR Po}

Parameter vektor ${ }^{\theta} \mathrm{P}_{0}$ didefinisikan sebagai berikut.

${ }^{\theta} \mathrm{P}_{0}={ }^{0} \mathrm{P}_{0}+\theta \mathrm{b}$

Di mana ${ }^{\circ} \mathrm{P}_{0}$ dan $\mathrm{b}$ adalah vekor vekor yang diketahui. Variasi pada vektor $\mathrm{P}_{0}$ hanya dapat mempengaruhi kefisibelan masalah program linier parametrik.

Prosedur untuk menentukan nilai kritis $\theta$ dimulai dengan menggunakan solusi ${ }^{0} \mathrm{X}_{\mathrm{B}}$, solusi yang berkaitan dengan $\theta=0$.

Misalkan $\alpha$ dan $\beta$, dua nilai kritis yang berurutan dari $\theta(\alpha \leq \beta)$, di mana diasumsikan bahwa solusi basis pada $\theta=$ a, diketahui dan diberikan oleh ${ }^{\alpha} \mathrm{X}_{\mathrm{B}}$. Kemudian kita menentukan nilai $\theta=\beta$, seperti berikut.
Solusi basis ${ }^{\alpha} \mathrm{X}_{\mathrm{B}}$ akan tetap fisibel untuk range $\theta>$ a selama kondisi ${ }^{\alpha} \mathrm{B}^{-1} \cdot{ }^{\theta} \mathrm{P}_{0} \geq 0$ dipenuhi. Sekarang ${ }^{\alpha} \mathrm{B}^{-1} \cdot{ }^{\theta} \mathrm{P}_{0}=$ $={ }^{\alpha} \mathrm{B}^{-1}\left({ }^{0} \mathrm{P}_{0}+\theta \mathrm{b}\right)$

$={ }^{\alpha} \mathrm{B}^{-1} \cdot{ }^{0} \mathrm{P}_{0}+\theta^{\alpha} \mathrm{B}^{-1} \cdot \mathrm{b}$

$={ }^{\alpha} B^{-1} \cdot{ }^{0} P_{0}+{ }^{\alpha} B^{-1} \alpha b+{ }^{\alpha} B^{-1} \theta b-{ }^{\alpha} B^{-1} \alpha b$

$={ }^{\alpha} B^{-1}{ }^{\alpha} P_{0}+(\theta-\alpha) \cdot{ }^{\alpha} B^{-1} b$

Misalkan $\left({ }^{\alpha} \mathrm{B}^{-1} \cdot{ }^{\alpha} \mathrm{P}_{0}\right)_{\mathrm{i}}$ dan $\left({ }^{\alpha} \mathrm{B}^{-1} \cdot \mathrm{b}\right)_{\mathrm{i}}$ berturut-turut elemen ke-i dari ${ }^{\alpha} B^{-1} \cdot{ }^{\alpha} \mathrm{P}_{0}$ dan ${ }^{\alpha} \mathrm{B}^{-1} \cdot \mathrm{b}$.

Karena ${ }^{\alpha} \mathrm{B}^{-1}{ }^{\alpha} \mathrm{P}_{0} \geq 0$, maka kondisi ${ }^{\alpha} \mathrm{B}^{-1}$. ${ }^{\alpha} \mathrm{P}_{0} \geq 0$ berlaku:

(1) Jika $\left({ }^{\alpha} \mathrm{B}^{-1} \cdot \mathrm{b}\right)_{\mathrm{i}} \geq 0$, untuk $\forall_{\mathrm{i}}$ dan " $\mathrm{X}_{\mathrm{B}}$ tetap fisibel untuk semua $\theta>a$.

(2) Jika $\left({ }^{\alpha} B^{-1} \cdot b\right)_{i}<0$, untuk sekurangkurangnya satu $\mathrm{i}$, dan terdapat nilai kritis $\theta=\beta$ yang diberikan oleh $\theta=\beta=$ $\alpha+\min \left\{\frac{-\left({ }^{\alpha} \mathrm{B}^{-1} \cdot{ }^{\alpha} \mathrm{P}_{\mathrm{O}}\right)}{\left({ }^{\alpha} \mathrm{B}^{-1} \cdot \mathrm{b}\right)_{\mathrm{i}}} \mid\left({ }^{\alpha} \mathrm{B}^{-1} \cdot \mathrm{b}\right)_{\mathrm{i}}<0\right\}$

Jadi untuk $\theta>\beta,{ }^{\beta} \mathrm{X}_{\mathrm{B}}$ tidak lagi fisibel. Pada $0=\beta$ solusi basis lain ${ }^{\beta} \mathrm{X}_{\mathrm{B}}$ dapat diperoleh dengan menggunakan dual metode simpleks, karena variabel yang dihubungkan dengan $\beta$ merupakan variabel pertama yang tidak fisibel, maka variabel ini dipilih sebagai variabel keluar pada $\theta=\beta$.

\section{Contoh:}

Tinjau masalah program linier parametrik pada $\mathrm{P}_{0}$.

Maks $\mathrm{Z}=3 \mathrm{x}_{1}+2 \mathrm{x}_{2}+5 \mathrm{x}_{3}$

terhadap $\mathrm{x}_{1}+2 \mathrm{x}_{2}+\mathrm{x}_{3}<430+100 \theta$

$3 \mathrm{x}_{1}+2 \mathrm{x}_{3}=460-200 \theta$

$\mathrm{x}_{1},+4 \mathrm{x}_{2}+\mathrm{x}_{6}=420+400 \theta$

$\mathrm{x}_{1}, \mathrm{x}_{2}, \ldots, \mathrm{x}_{6} \geq 0$

Di sini $x_{4}, x_{5}, x_{6}$ adalah variabel-

variabel slack dan ${ }^{\theta} \mathrm{P}_{0}=\left(\begin{array}{l}430 \\ 460 \\ 420\end{array}\right)+\theta\left(\begin{array}{c}100 \\ -200 \\ 400\end{array}\right)$

Jika $\theta=0$ dan masalah program linier di atas di selesaikan dengan metode simpleks, maka Tabel solusinya sebagai berikut:

Tabel 3. Solusi Masalah 
Desimal, 2 (1), 2019 - 74

Adolf T. Simatupang

\begin{tabular}{ccccccccc}
\hline Basis & $\mathrm{z}$ & $\boldsymbol{x}_{\mathbf{1}}$ & $\boldsymbol{x}_{\mathbf{2}}$ & $\boldsymbol{x}_{\mathbf{3}}$ & $\boldsymbol{x}_{\mathbf{4}}$ & $\boldsymbol{x}_{\mathbf{5}}$ & $\boldsymbol{x}_{\mathbf{6}}$ & Solusi \\
$\mathrm{z}$ & 1 & 4 & 0 & 0 & 1 & 2 & 0 & 1350 \\
$\mathrm{X} 2$ & 0 & $-1 / 4$ & 1 & 0 & $1 / 2$ & $-1 / 4$ & 0 & 100 \\
$\mathrm{X}_{3}$ & 0 & $3 / 2$ & 0 & 1 & 0 & $1 / 2$ & 0 & 230 \\
$\mathrm{X}_{6}$ & 0 & 2 & 0 & 0 & -2 & 1 & 1 & 20 \\
\hline
\end{tabular}

Menentukan nilai kritis pertama $\theta^{\prime}>0$

Disini ${ }^{0} X_{B}=\left(\begin{array}{c}100 \\ 230 \\ 20\end{array}\right)$, dan ${ }^{0} B^{-1} \cdot b=$

$\left(\begin{array}{ccc}\frac{1}{2} & -\frac{1}{4} & 0 \\ 0 & \frac{1}{2} & 0 \\ -2 & 1 & 1\end{array}\right)\left(\begin{array}{c}100 \\ -200 \\ 400\end{array}\right)=\left(\begin{array}{c}100 \\ -100 \\ 0\end{array}\right)$

Maka $\theta^{\prime}=\alpha+\min$

$\left\{\frac{-\left({ }^{\mathrm{O}} \mathrm{B}^{-1} \cdot \mathrm{P}_{\mathrm{O}}\right)}{\left({ }^{\mathrm{O}} \mathrm{B}^{-1} \cdot \mathrm{b}\right)_{\mathrm{i}}} \mid\left({ }^{\mathrm{O}} \mathrm{B}^{-1} \cdot \mathrm{b}\right)_{\mathrm{i}}<0\right\}=0+\min \left(-, \frac{-230}{-100}\right)$

$=23$

Nilai kritis pertama $\theta^{\prime}$ ini berhubungan dengan variabel basis $\mathrm{x}_{3}$, sehingga $\mathrm{x}_{3}$ merupakan variabel keluar,

Untuk $\theta^{\prime}=2,3$, maka: ${ }^{\theta} \mathrm{P}_{0}={ }^{0} \mathrm{P}_{0}+\theta \mathrm{b}=$ $\left(\begin{array}{l}430 \\ 460 \\ 420\end{array}\right)+2,3\left(\begin{array}{c}100 \\ -200 \\ 400\end{array}\right)=\left(\begin{array}{c}660 \\ 0 \\ 1340\end{array}\right)$

dan solusi basisnya adalah ${ }^{\theta} \mathrm{X}_{\mathrm{B}}={ }^{0} \mathrm{~B}^{-1}{ }^{\theta} \mathrm{P}_{\mathrm{O}}=$ $\left(\begin{array}{ccc}\frac{1}{2} & -\frac{1}{4} & 0 \\ 0 & \frac{1}{2} & 0 \\ -2 & 1 & 1\end{array}\right)\left(\begin{array}{c}600 \\ 0 \\ 1340\end{array}\right)=\left(\begin{array}{c}330 \\ 0 \\ 20\end{array}\right)$

Jadi solusi di atas dalam bentuk Tabel untuk $0 \leq \theta \leq 2,3$ sebagai berikut.

Tabel 4. Solusi Nilai-Nilai Variabel

\begin{tabular}{ccccccccc}
\hline Basis & $\mathbf{z}$ & $\boldsymbol{x}_{\mathbf{1}}$ & $\boldsymbol{x}_{\mathbf{2}}$ & $\boldsymbol{x}_{\mathbf{3}}$ & $\boldsymbol{x}_{\mathbf{4}}$ & $\boldsymbol{x}_{\mathbf{5}}$ & $\boldsymbol{x}_{\mathbf{6}}$ & Solusi \\
$\mathrm{z}$ & 1 & 4 & 0 & 0 & 1 & 2 & 0 & 660 \\
$\mathrm{X} 2$ & 0 & $-1 / 4$ & 1 & 0 & $1 / 2$ & $-1 / 4$ & 0 & 330 \\
$\mathrm{X} 3$ & 0 & $3 / 2$ & 0 & 1 & 0 & $1 / 2$ & 0 & 0 \\
$\mathrm{X}_{6}$ & 0 & 2 & 0 & 0 & 2 & 1 & 1 & 20 \\
\hline
\end{tabular}

Untuk $0 \leq \theta \leq \theta^{\prime}$, solusi tetap fisibel

$\left(\begin{array}{l}\mathrm{x}_{2} \\ \mathrm{x}_{3} \\ \mathrm{x}_{4}\end{array}\right)={ }^{0} \mathrm{~B}^{-1}{ }^{\theta} \mathrm{P}_{0}={ }^{0} \mathrm{~B}^{-1} \cdot{ }^{0} \mathrm{P}_{0}+\theta^{0} \mathrm{~B}^{-1} \cdot \mathrm{b}=$

${ }^{0} \mathrm{~B}^{-1}\left(\mathrm{P}_{0}+\theta \mathrm{b}\right)=\left(\begin{array}{c}100 \\ 230 \\ 20\end{array}\right)+\theta^{\prime}\left(\begin{array}{c}100 \\ -100 \\ 0\end{array}\right)$
Pada $\theta=\theta^{\prime}=2,3$

$\beta \mathrm{X}_{\mathrm{B}}=\left(\begin{array}{c}330 \\ 0 \\ 20\end{array}\right)$

Untuk $0>\theta^{\prime}=2,3$ maka pada konstrain kedua nilai $\mathrm{x}_{3}<0$ sehingga masalah program linier di atas tidak fisibel untuk $\theta$ $>\theta^{\prime}=2,3$. Jadi masalah program linier di atas tetap fisibel untuk $0 \leq \theta \leq 2,3$.

Hasil di atas dapat dinyatakan seperti Gambar 2 sebagai berikut.

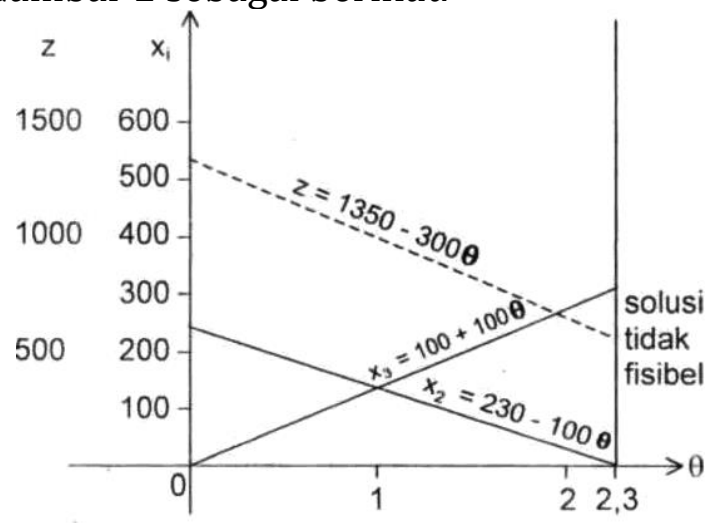

Gambar 2. Diagram Solusi Variabel

\section{PROGRAM LINIER KONSTRAIN KIRI PARAMETRIK}

Masalah program linier sebelum diberi parameter adalah

Maks $\mathrm{Z}=\mathrm{C} \cdot \mathrm{X}$

terhadap $(\mathrm{A}, \mathrm{I}) \mathrm{X}=\mathrm{P}_{0}, \cdot \mathrm{P}_{0} \geq 0$

$\mathrm{X}>0$

Disini kita membahas variasi linier vektor non basis $P_{J}$ dari A. Misalkan $\theta>0$ adalah parameter variasi. Maka fungsi-fungsi linier dalam koefisien program linier di atas menjadi:

${ }^{\theta} \mathrm{P},={ }^{\mathrm{O}} \mathrm{P},+\theta \mathrm{b}_{\mathrm{j}}$

Dimana vektor non basis $\mathrm{P}_{\mathrm{j}}$ dari $\mathrm{A}$, dan ${ }^{\mathrm{O}} \mathrm{Pj}$, $b_{\mathrm{j}}$ adalah vektor-vektor yang diketahui.

Disini kita meninjau $\theta>0$. Untuk $\theta<0$ peninjauannya dilakukan dengan cara yang sama.

Selanjutnya masalah yang kita tinjau adalah masalah memaksimumkan, sedangkan masalah meminimumkan dapat ditinjau dengan cara yang sama. 
Desimal, 2 (1), 2019 - 75

Adolf T. Simatupang

VARIASI-VARIASI PADA VEKTOR NON BASIS $P_{\mathbf{j}}$ DARI A

Parameter non basis ${ }^{0} \mathrm{P}_{\mathrm{j}}$ diberikan sebagai berikut:

${ }^{\theta} \mathrm{Pj}={ }^{O} \mathrm{P}_{\mathrm{j}}+\theta \mathrm{b}_{\mathrm{j}}$

Dimana ${ }^{0} P_{j}$ dan $b_{j}$ adalah vektor-vektor yang diketahui.

Tahap pertama kita menyelesaikan program linier untuk $\theta=0$. Karena setiap perubahan vektor non basis $\mathrm{P}_{j}$ hanya mempengaruhi nilai $\mathrm{Z}_{\mathrm{j}}--\mathrm{C}_{\mathrm{j}}$, maka kita hanya melihat keoptimalan $\mathrm{P}_{\mathrm{j}}$. Perubahan di sini, jika kita sudah memiliki nilai kritis pertama $\theta^{\prime}$, vektor non basis $\mathrm{P}_{\mathrm{j}}$ akan menjadi vektor basis untuk $\theta>\theta^{\prime}$. Jadi pembahasan tidak dapat dilanjutkan keseluruhan range 0 .

Sehingga pembahasan disini hanya menunjukkan bagaimana nilai $\theta^{\prime}$.

Tinjau ${ }^{0} X_{B}$, selain basis optimal untuk $0=$ 0.

Solusi ini akan tetap basis selama

${ }^{0} \mathrm{Z}_{\mathrm{j}}-\mathrm{C}_{\mathrm{j}}=\mathrm{C}_{\mathrm{B}} \cdot{ }^{0} \mathrm{~B}^{-1} \cdot{ }^{\theta} \mathrm{P}_{\mathrm{j}}-\mathrm{C}_{\mathrm{j}}>0$

$=\mathrm{C}_{\mathrm{B}} \cdot{ }^{0} \mathrm{~B}^{-1} \cdot\left({ }^{O} \mathrm{P}_{\mathrm{j}}+\theta \mathrm{b}_{\mathrm{j}}\right)-\mathrm{C}_{\mathrm{j}} \geq 0$

0

$=\mathrm{C}_{B} \cdot{ }^{0} \mathrm{~B}^{-1} \cdot{ }^{0} \mathrm{P}_{\mathrm{j}}+\theta \mathrm{C}_{\mathrm{B}} \cdot{ }^{0} \mathrm{~B}^{-1} \mathrm{~b}_{\mathrm{j}}-\mathrm{C}_{\mathrm{j}} \geq$

Karena ${ }^{0} \mathrm{Z}_{\mathrm{j}}-\mathrm{C}_{\mathrm{j}}=\mathrm{C}_{\mathrm{B}} \cdot{ }^{0} \mathrm{~B}^{-1} \cdot{ }^{o} \mathrm{P}_{\mathrm{j}}-\mathrm{C}_{\mathrm{j}} \geq 0$, yaitu solusi optimal untuk $\theta=0$, maka diperoleh

(1) Jika $C_{B} \cdot O B-1 \cdot b j \geq 0$, untuk $\forall j, O X_{B}$ tetap optimal untuk setia $\theta>0$.

(2) Jika $\mathrm{C}_{\mathrm{B}} \cdot \mathrm{OB}-1 \cdot \mathrm{bj}<0$, untuk sekurang kurangnya satu j, maka terdapat nilai kritis $\theta^{\prime}$ yang diberikan oleh

$\theta^{\prime}=\min \left\{\frac{-\left({ }^{O} \mathrm{Z}_{\mathrm{j}}-\mathrm{C}_{\mathrm{j}}\right)}{\mathrm{C}_{\mathrm{B}} \cdot{ }^{\mathrm{O}} \mathrm{B}^{-1} \mathrm{~b}_{\mathrm{j}}} \mid \mathrm{C}_{\mathrm{B}} \cdot{ }^{{ }^{O} \mathrm{~B}^{-1} \mathrm{~b}_{\mathrm{j}}<0}\right\}$

Dimana ${ }^{0} \mathrm{X}_{\mathrm{B}}$ bukan lagi optimal.

Untuk $\theta=\theta^{\prime}$, solusi optimal lain didapat dengan memasukkan vektor non basis $\mathrm{P}_{\mathrm{j}}$ yang berhubungan dengan $\theta^{\prime}$ ke dalam solusi.

\section{Contoh:}

Tinjau masalah Maks $\mathrm{Z}=3 \mathrm{x}_{1}+2 \mathrm{x}_{2}+3 \mathrm{x}_{3}$

terhadap $(1+0) \mathrm{x}_{1}+2 \mathrm{x}_{2}+\mathrm{x}_{3} \leq 430$

$$
\begin{gathered}
(3-0) \mathrm{x}_{1}+2 \mathrm{x}_{3} \leq 460 \\
\mathrm{x}_{1}+4 \mathrm{x}_{2} \quad \leq 420 \\
\mathrm{x}_{1}, \mathrm{x}_{2}, \mathrm{x}_{3}>0
\end{gathered}
$$

Untuk $\theta=0$, masalah program linier di atas dalam bentuk standarnya sebagai berikut Maks $\mathrm{Z}=3 \mathrm{x}_{1}+2 \mathrm{x}_{2}+5 \mathrm{x}_{3}$

Terhadap

$\mathrm{x}_{1}+2 \mathrm{x}_{2}+\mathrm{x}_{3}+\mathrm{x}_{4}$

$(1+0)$

430

420

$$
\begin{array}{ll}
(3-0) \mathrm{x}_{1}+2 \mathrm{x}_{3} & +\mathrm{x}_{5} \\
=460 & +\mathrm{x}_{6}=
\end{array}
$$

$$
\mathrm{X}_{1}, \mathrm{X}_{2}, \ldots, \mathrm{x}_{6}>0
$$

Di $\operatorname{sini} \mathrm{x}_{4}, \mathrm{x}_{5}, \mathrm{x}_{6}$ adalah variabel-variabel slack. Jika $\theta=0$ dan masalah program linier di atas diselesaikan dengan metode simpleks maka Tabel solusi adalah sebagai berikut:

Tabel 5. Solusi Nilai-Nilai Variabel

\begin{tabular}{ccccccccc}
\hline Basis & $\mathrm{z}$ & $\boldsymbol{x}_{\mathbf{1}}$ & $\boldsymbol{x}_{\mathbf{2}}$ & $\boldsymbol{x}_{\mathbf{3}}$ & $\boldsymbol{x}_{\mathbf{4}}$ & $\boldsymbol{x}_{\mathbf{5}}$ & $\boldsymbol{x}_{\mathbf{6}}$ & Solusi \\
$\mathrm{z}$ & 1 & 4 & 0 & 0 & 1 & 2 & 0 & 1350 \\
$\mathrm{x} 2$ & 0 & $-1 / 4$ & 0 & 0 & $1 / 2$ & $-1 / 4$ & 0 & 100 \\
$\mathrm{x}_{2}$ & 0 & $3 / 2$ & 0 & 1 & 0 & $1 / 2$ & 0 & 230 \\
$\mathrm{x}_{6}$ & 0 & 2 & 0 & 0 & -2 & 1 & 1 & 20 \\
\hline
\end{tabular}

Disini $\quad \mathrm{OXB}=\left(\begin{array}{l}\mathrm{x}_{2} \\ \mathrm{x}_{3} \\ \mathrm{x}_{6}\end{array}\right)=\left(\begin{array}{c}100 \\ 230 \\ 20\end{array}\right)$

dan

Untuk $\theta>0$

$$
\begin{aligned}
&\left({ }^{O} Z_{1}-C_{1}\right)=C_{B} \cdot{ }^{o} B^{-1} \cdot{ }^{O} P_{1}-C_{1} \\
&=(2,5,0)\left(\begin{array}{ccc}
\frac{1}{2} & -\frac{1}{4} & 0 \\
0 & \frac{1}{2} & 0 \\
-2 & 1 & 1
\end{array}\right) \cdot\left(\begin{array}{c}
1+\theta \\
3-\theta \\
1
\end{array}\right)-1 \\
&=(1,2,0)\left(\begin{array}{c}
1+\theta \\
3-\theta \\
1
\end{array}\right)-3 \geq 0 \\
& \text { atau } 4-\theta \geq 0 .
\end{aligned}
$$

ini memberikan $\theta^{\prime}=4$.

Jadi masalah program llinier parametrik di atas pada vektor non basis $\mathrm{P}_{1}$, solusi tetap optimal dengan nilai kritis pertama adalah $0<\theta<4$. 


\section{Dengan cara lain}

Menentukan nilai kritis pertama $\theta>0$, karena parameter hanya dikaitkan pada vector non basis maka:

$\mathrm{CB} \cdot \mathrm{OB}-1 \cdot \mathrm{bj}=(2,5,0)\left(\begin{array}{ccc}\frac{1}{2} & -\frac{1}{4} & 0 \\ 0 & \frac{1}{2} & 0 \\ -2 & 1 & 1\end{array}\right) \cdot\left(\begin{array}{c}1 \\ -1 \\ 0\end{array}\right)$

$$
=(1,2,0)\left(\begin{array}{c}
1 \\
-1 \\
0
\end{array}\right)=-1<0
$$

Jadi $\theta=\min \left\{\frac{-\left({ }^{\circ} \mathrm{Z}_{1}-\mathrm{C}_{1}\right)}{\mathrm{C}_{\mathrm{B}} \cdot{ }^{\mathrm{O}} \mathrm{B}^{-1} \mathrm{~b}_{1}} \mid \mathrm{C}_{\mathrm{B}} \cdot{ }^{\mathrm{o}} \mathrm{B}^{-1} \mathrm{~b}_{1}<0\right\}=$ $\min \left\{\frac{-4}{-1}\right\}=4$

Sehingga masalah program linear parametric di atas pada vector non basis P1, solusi tetap optimal dengan nilai kritis pertama adalah $0 \leq \theta^{\prime} \leq 4$.

\section{SIMPULAN DAN SARAN}

Berdasarkan hasil pembahasan dapat disimpulkan bahwa pada masalah program linier biasa konstanta program linier adalah tetap, maka pada program linier parametrik ini dapat dikatakan suatu masalah program linier yang konstantanya dapat berubah-ubah tanpa harus mengulangi perhitungan dari awal. Jadi dapat dihitung sekaligus dengan sekali perhitungan. Perhitungan program linier parametrik baik itu program linier fungsi objektif parametrik maupun pada program linier pembatas kanan parametrik dan program linier pembatas kiri parametrik, kita cari dahulu solusi optimal program linier tanpa parametrik. Jika ada solusi optimalnya maka kita dapat mencari interval-interval nilai-nilai parameter tersebut menjadi solusi optimal. Jika kita ingin merubah suatu konstanta pada masalah program linier parametrik tersebut, maka kita dapat merubah parameternya dan kemudian kita mencari nilai parameternya tersebut pada interval yang ada. Dan solusi optimalnya adalah solusi yang berkaitan dengan interval dimana parameter tersebut berada.

Berdasarkan kesimpulan penelitian, ada beberapa hal yang perlu peneliti sarankan yaitu agar peneliti selanjutnya dapat melakukan penelitian dengan cakupan yang lebih luas

\section{DAFTAR PUSTAKA}

Ayres, F. (1984). Matriks. Bandung: ITB.

Dhawan, S. (1975). Linier Programming. New Delhi.

Hadly, G. (1962). Linier Programming. Canada.

Indriani, D., Suyitno, H., \& Mashuri. (2013). Analisis Metode Karmarkar Untuk Menyelesaikan Masalah Program Linier. Jurnal Mipa, 36(1), 98-106.

Suwirmayanti, N. L. G. P. (2017). Aplikasi Optimasi Produksi Menggunakan Metode Simpleks Berbasis WEB. Techno Com, 17(1), 61-69.

Taha, H. A. (2003). Operations Research An Introduction. New York: Macmillan Inc.

Windarti, T. (2013). Pemodelan Optimalisasi Produksi Untuk Memaksimalkan Keuntungan Dengan Menggunakan Metode Program Linier. Spektrum Industri : Jurnal Ilmu Pengetahuan Dan Penerapan Teknik Industri, 11(2), 148-159. 